\title{
A Comparative Study on Teacher's Narrative of School Curriculum Development in South Korea and China
}

\author{
Li Xiaohui ${ }^{1}$ \\ ${ }^{1}$ Student, Kyungpook National University, South Korea, lovely824hui@msn.cn
}

\begin{abstract}
This study is aimed to compare the difficulties and differences between South Korean and Chinese teachers in the School Curriculum Development. For this purpose, a narrative inquiry, a method of exploring individual experiences, was used. Narrative inquiry is a method of exploring individual experiences. In this study, the narrative exploration procedure presented by Clandinin and Connelly (2000) was used, and selected three Korean teachers, three Chinese teachers, having a total of 6 participants as the primary field texts. The results showed that; first, China has improved and tried harder in that the development of the school curriculum requires a demand for teachers' expertise. Second, as a "difficulty" in developing school curriculum, South Korea and China are influenced by various factors, including the personal, contextual and empirical dimensions of teachers, under different political and social backgrounds. Third, South Korea and China face the same difficulties about 'teacher relations'. Fourth, in terms of the principal's leadership, Korea and China have a common point that the principal determines the quality of the school curriculum management. Fifth, the expectations of teachers in the development of school curriculum are that Korean and Chinese teachers are also students-oriented, and they expect to expand teacher research and education opportunities related to school curriculum development, and to develop and implement related programs for school curriculum development.
\end{abstract}

Keywords: School Curriculum Development, South Korea, China, Teacher's narrative, narrative inquire.

\section{Introduction}

\subsection{Necessity and Purpose of Research}

Korea and China have historically exchanged in many ways. As Korea and China established diplomatic relations in 1992, exchanges between the two countries have been more active in various fields, including economy, industry, politics, society, and culture. Beginning in the 21 st century, governments around the world are becoming more closely connected.

For teachers worldwide, the development of classes and school curriculum is one of the essential parts of the curriculum operation. For teachers, the development of school curriculum refers to creating detailed curriculum documents for the schools organized according to the national level, regional characteristics, school conditions, and students' characteristics.

In this study, the author would like to reveal the commonalities and differences between Korean and Chinese teachers' experience in the course development activities at school education sites through narrative inquire methods. Narrative inquire method is based on "telling" and "retelling" the experiences that humans experience in their lives. It is a method of exploring "reliving"[1]. In

Received: November 07, 2020; $1^{\text {st }}$ Review Result: December 31, 2020; $2^{\text {nd }}$ Review Result: February 15, 2021 Accepted: March 29, 2021 
response, Clandinon stated, 'Narrative inquiry is a way of understanding human experience, nothing more or less.'[2] Everyone has their own experience. In particular, teachers in other Korea and China reveal commonalities and differences through narrative exploration methods. I think these commonalities and differences are worth studying and meaningful as the beginning of the study.

In this study, we followed the narrative exploration procedure presented by Clandinin and Connelly (2000), and selected three Korean teachers, three Chinese teachers, A total of 6 participants as the primary field texts. After that, the research followed the narrative inquire process. In this process, when Korean and Chinese teachers search for many studies on the curriculum development process, there are some independent studies in each country. Still, Among them, it was recognized reflectively that not many of them describe teachers' interest and practice level through quantitative research or experience in an effective and efficient school curriculum development. This reflective perception became the starting point of this study.

Therefore, this study explores the experiences teachers experience in the development of school curriculum using narrative inquire methods. In addition, since the application of the narrative inquiry method is not common in the field of curriculum research, the purpose of this research was to find the application process and significance of the narrative inquiry method in curriculum research.

\subsection{Research Problem}

1) What are the difficulties Korea teachers feel in the process of developing school curriculum, the degree of state control, and what are the expectations for curriculum development?

2) What are the difficulties Chinese teachers feel in the process of developing school curriculum, the degree of state control, and what are the expectations for curriculum development?

3) What are the similarities and difference between narrative of Korea and Chinese teachers in the process of developing school curriculum?

\section{Research Method}

In this study a narrative inquiry method was used to find out the commonalities and differences between various difficulties and demands for professionalism in the school curriculum development precess between Korea and Chinese teachers, and further to reveal the meaning of education.

\subsection{Narrative Inquiry Method}

Narrative inquiry is a method of exploring individual experiences. It is a process of living a new life through 'talking' and 'talking again'[1][3], where humans form the meaning of their own experiences through narratives.

\subsection{Research Participants}

A total of 6 participants were selected as 3 Korean teachers and 3 Chinese teachers. Since it is not possible to meet with the Chinese research participants, they were selected through video chat. Research participants in Korea were selected from field teachers attending graduate school classes with researchers. In addition, Korean and Chinese research participants have similar service years as secondary school teachers and can think of educational implications due to difficulties and demands for the school curriculum development process, and are judged to be appropriate for forming rapo with researchers. The researcher explained the purpose of the study to the selected study participants and asked for consent. Table 1 shows the background of the study participants. 
[Table 1] Personal Information

\begin{tabular}{|c|c|c|}
\hline Participants & Education career years & Working organization \\
\hline (Korea) Teacher A & 9 years & Middle School \\
\hline (Korea) Teacher B & 6 years & Middle School \\
\hline (Korea) Teacher C & 7 years & Middle School \\
\hline (China) Teacher D & 6 years & Middle School \\
\hline (China) Teacher E & 6 years & Middle School \\
\hline (China) Teacher F & 11 years & \\
\hline
\end{tabular}

\subsection{Research Procedure}

In this study, the research procedure and research results were derived based on the narrative inquiry process of Clandin and Connelly[1]. The research procedure is shown in Figure 1.

\begin{tabular}{l}
\hline Step 1: Exist in the field \\
- Getting into the study. \\
-Negotiate relationship between researchers and research participants, objective negotiation, implementation \\
negotiation, and negotiate ways to be useful.
\end{tabular}

\section{Step 2: Move from field to field text}

- There are limited environmental conditions, but to be present in the subject's story space as much as possible, to experience the experience.

\begin{tabular}{|l|}
\hline Step 3: configure the field text \\
\hline \\
- The construction of field text is an interpretative process. \\
- field text in the form of teachers' stories, autobiographical form field text, life experience as a source of field text.
\end{tabular}

\begin{tabular}{|l|}
\hline Step 4: From field text to research text \\
\hline - Justification, site, method, analysis-interpretation, theoretical literature. \\
\hline
\end{tabular}

\section{Step 5: Configure the study text}

- Describe the study text.

[Fig. 1] Research Procedure 


\subsection{Data Collection}

The data collection period for this study was conducted for a total of 4 weeks from November 7 , 2019 to November 28, 2019.

The purpose of this study was to explore the difficulties felt by Korean and Chinese teachers in the development of school education curriculum, the degree of state control, and expectations for curriculum development. The meetings were held with Korean teachers every Thursday before graduate school classes, and video chat meetings with Chinese teachers were held every Wednesday after finishing their school works. Whether it was a research meeting with Korea teachers or an internet video chat meeting with Chinese teachers, the conversations between researchers and participants were recorded and data was collected.

\subsection{Data Processing and Analysis}

In this study, Denzin's triangulation method was used to enhance the validity and reliability of the research results. The process of deriving research results is as follows.

First, the intimacy-rapo with the study participants was formed, and the purpose of the research was explained to the study participants. As the study participants were divided into Korean and Chinese teachers, there were times when difficulties were felt due to restrictions on environmental conditions. Second, research participants wrote reflective journals, researchers repeatedly read collected reflective journal writing, nominate similar topics and create the meaning of experience shared among study participants. Similar topics that go through nomadic process are presented as shown in Table 2 below.

[Table 2] Nomadic Pseudo-Topic

1) The meaning and legal personality of school curriculum

2) Aspects of the school curriculum development process

(1) The role of teachers

(2) Difficulties in developing school curriculum

(3) Positive points in the development of school curriculum

3) School culture on the course of school curriculum development

(1) The level of participation and cooperation of teachers, and atmosphere of confrontation

(2) Principal's leadership

(3) Degree of involvement of parents

(4) Process of collecting opinions from students

(5) The degree of control or management by the national government

4) Teachers' expectations for the development of school curriculum

(1) What to expect

(2) The degree of invasion and encouragement of teacher autonomy

(3) Prospects for school development

Third, anti-objective analysis of coating data by content and subject, categorizing the subject, and interpreting the meaning. 
In order to increase the validity of the research in this research process, the researcher informed the research participants of the topics or research results found through analysis, and found misrepresented or interpreted parts, and received confirmation and criticism from the research participants.

\section{A Narrative Analysis of Teachers' Curriculum Development in China and Korea}

This study examines the factors affecting teachers in the school curriculum development process by Korean and Chinese teachers through the steps of moving from field to field text, constructing field text, from field text to research text, and finally constructing research text. It was intended to be searched, and the difficulties and deficiencies related to the teacher's expertise are examined.

\subsection{Narrative Features of Teachers in China}

\subsubsection{The Demand for Professional Knowledge of Teachers in the Development of School Curriculum}

Teachers with long experience in the classroom do not play a role in curriculum development. In training seminars, opportunities for continued professional development are confined outside of school and within state control. (Teacher D. 2019. 11. 06. During video chat meeting).

Although the professional knowledge of the teacher is important, most middle schools currently teach classes based on exams under the application system for entering high school. Each subject is supposed to be taught in certain way in order to increase the entrance rate(Teacher F. 2019. 11. 06. During video chat meeting).

In the course of school curriculum development, Chinese research participants differ in their professionalism according to their teaching experience. For teachers, the quality of curriculum development varies depending on the level of knowledge and understanding of the teaching field and the level of proficiency in teaching methods. For teachers, the composition of the curriculum and the development of teaching materials constitute an important and fundamental factor of the teacher's role[4]. Therefore, it is required to provide teacher training opportunities for the development and operation of school curriculum, establish appropriately equipped support centers, expand continuous education opportunities, and develop and implement school curriculum programs.

\subsubsection{Teacher's Challenges on Policy and Implementation}

Currently, the education system in China is implementing compulsory education for nine years. It is compulsory to study from elementary to junior high school, but if you want to study after graduating from junior high school, you must pass the national exam (中考) to give you the qualifications to enter and study. In order to improve, there are many cases of developing and operating a test-oriented school curriculum.

He said that there was little I could have had an impact on what was happening throughout the school. He said he feels that there is a barrier between policy and what we (teachers) know and experience as professionals (during a video chat meeting on November 13, 2019).

For teachers, it is an important matter to influence policy direction at each level of the system as to the challenges they face in policy and practice, at the school and district level in which they work, and across the country[5].

\subsubsection{Relations with Teachers}

The following records describe Chinese teacher D's relationship with teachers in the development of school curriculum.

For teachers, there are professional teachers who are passionate about the philosophy and passion 
for education, teachers who formally engage in inertia as a means of living, and teachers who are interested in promotion, and teachers who are not interested in promotion or have given up at all. . So, curriculum development and operation are different. In this case, the relationship with teachers appears difficult due to awareness, educational ideology, and personal circumstances among teachers in the course of school curriculum development (during November 20, 2019 video chat meeting).

Teachers are said to be more passive than other faculty colleagues. The evaluation of one's own work and professional development is given from the outside, and the reason that teachers become aware of the meaning and influence of professional communication between teachers is because they recognize the problems of such an approach.

In addition, since the school atmosphere is different for each school, there is a need for improvement in that teachers must play a leading role with peers in the teacher group for school curriculum development.

\subsubsection{The Strong Influence of the Principal}

Many personnel are involved in the development and management of school curriculum. In particular, under the background of China's socialist state, principals and informal leaders greatly influence the development and operation of the curriculum.

The principal has a strong influence and many teachers are influenced by his views. Therefore, when the principal's governance is strict, it may be difficult to expect effective development and operation of a new curriculum in an atmosphere where teachers are afraid of failure and are difficult to take on challenges(Teacher F. During the video chat meeting on November 27, 2019).

Teachers directly plead with the principal to provide support and encouragement. Quite a few teachers require principals to participate in the professional development process. This should show that the principal is not consistent with that attitude. This is because the principals already know the skills to lead the school. According to political considerations, the principal is appointed, and for this reason, it is said that faculty members should receive support and audit regardless of the principal's political opinion.

Of course, teachers want to be free from political prejudice and they want to respond to consultations on issues of policy and implementation. In this study, teachers presented a clear perspective on an environment that would improve student performance and allow innovative practices.

\subsubsection{Teachers' Expectations for the Development of School Curriculum}

The core expectation is to provide opportunities for quality professional development to teachers who participated in this study. Teacher F said the story below.

Teacher professional development opportunities are important for teachers in remote locations, especially new teachers. In this kind of education, teachers meet and learn, and teachers who have acquired such expertise become more actively involved. It is said that such a system is necessary in a situation where it is difficult for young teachers to come in and keep staying(During a video chat meeting on November 27, 2019).

Another teacher E told the story below.

Teachers said they needed the right to make their own decisions about professional development. Participating teachers for professional development demand to have the right to decide when to receive education and to choose whether to participate, but it needs to be guaranteed to ensure that teachers have equal opportunities for learning or the right to choose.(During a video chat meeting on November 27, 2019). 


\subsection{The Narratives of Teachers in Korea}

\subsubsection{The Role of Teachers in the Development of School Curriculum}

Teacher A told the following story about the teacher's role in the development of school curriculum.

Based on the developed curriculum developed at the national and regional levels, teachers should take into account the human, material, and environmental support that the school has, and actively participate in developing the curriculum by reflecting the learner's situation(November 07, 2019. Faceto-face interview).

List as follows, as teachers themselves are loyal as experts.

1) Passion-spending extra time in meeting with students.

2) Value the individual needs of each student.

3) Responsibility for imparting knowledge, attitudes and values.

4) Maintain and supplement knowledges as an expert.

5) Participating in the school community

\subsubsection{Difficulties in the Development of School Curriculum}

About the challenges of developing the school curriculum, Teacher B said as the following.

In some cases, school curriculum development is used for school evaluation or school performance, so there are cases where awareness of school curriculum development is poor (November 07, 2019 face-to-face interview).

Also, Teacher C said the following story.

Teachers who don't feel the necessity of developing the school curriculum itself and think that it is okay to follow the existing ones, sometimes require more persuasion for development than development (November 07, 2019 face-to-face interview).

The school principal's Inspection for school has often been pointed out as a cause of misery for teachers. It is recommended to do a school self-assessment, but it is adjusted and tested according to this inspection[6].

It is also the operation and practice of a developed curriculum that many teachers are already familiar with. So in the future, it is necessary to connect with an atmosphere of innovation in order to share any practical action that will help teachers actively participate in the development of school curriculum.

\subsubsection{The Degree of Teachers' Participation, Cooperation, and an Atmosphere of Confrontation}

Teacher A talked about the level of participation, cooperation, and confrontation among teachers in the development of school curriculum.

There is still a school culture that does not try to actively participate, thinking that the development of school curriculum is the job of some teachers in charge. In other cases, they are interested in the school curriculum, but they avoid participation in development due to lack of professional knowledge about the curriculum (November 14, 2019 face-to-face interview).

Teacher cooperation is not accidental. Collaboration can be most effective when it becomes part of the day-to-day work of the school. In addition, collaboration isn't just about meeting teachers in teams. The key should be to improve student learning. Teams for Collaboration provide teachers with the opportunity to participate in the ongoing questioning process.

As a result, it is necessary to develop a culture in which teachers collaborate as professionals within the school. In schools, teachers can unlock their internal potential and, in doing so, can expand the school's capacity to accommodate the needs of students and further enhance educational outcomes. 


\subsubsection{Principal's Leadership}

Stories about the principal's leadership, in Korea, like China, the principal has an important role. Teacher $\mathrm{C}$ said the following story.

In the process of developing the school curriculum, the principal's leadership is paramount. If there is a strong educational philosophy of the principal who has a correct understanding of the school, that is, a vision, then the development of the school curriculum can encourage the understanding and participation of members, and can also involve them in the development process (November 21, 2019. Face-to-face interview).

Korea has national, regional, and school curricula. From the point of view of decentralized leadership, leadership is an act of cooperation and communication, through which the organization is maintained, problems are solved, and practices are improved[6]. It allows you to provide developmental support for teachers away from the detailed supervisory task of the principal. In such an environment, an atmosphere of trust can grow between the official leadership of the school and the teachers in the classroom. Therefore, it is necessary to make an effort to create a culture of school staff that fosters teachers' leadership skills.

\subsubsection{Teachers' Expectations for the Development of School Curriculum}

It is expected that if teachers secure autonomy and avoid responsibility and authority based on the school curriculum, they will be able to participate in the development more actively and more passionately (Teacher A, Nov. 21, 2019.Face-to-face interview).

In the development of school curriculum, teachers expect to achieve the educational goals required by countries, regions, and schools by reflecting the characteristics of learners in the school, various resources, and environments (Teacher B, Nov. 21, 2019. Face-to-face interview).

As an expert, any agenda setting for the future of the teaching profession should take into account the balance between satisfaction and dissatisfaction. In "Public Policy Research Report"[7], the concept of' the satisfaction factor in the heart' was used, in order to extract the elements essential for teachers to feel satisfaction as experts. According to the report, burnout in a professional job can be reduced by increasing the positive elements of the job. Teachers have the point that the satisfaction factor in their minds can make a difference in children's lives.

The continuing professional development of teacher is important to discontinuous training or personal skills development program, but rather a focus on educational reform, such as securing legal provisions for support for professional development. We also look forward to the fact that teachers, as experts, should listen to individual or collective voices.

\section{Conclusions}

So far, the author has been exploring narratives about the experiences of Korean and Chinese teachers on the development of curriculum in schools. This study began with the recognition that there is a lack of research on the vivid experiences of Korean and Chinese teachers in the development of school curriculum. Through this study, aspects such as difficulties, demands, state control, and expectations for the development of the school curriculum were analyzed. To achieve this purpose, the following conclusions were drawn by collecting and analyzing contents through narrative inquiry.

First, in terms of the need for school curriculum development and teacher expertise, China has more to do. Currently, China has a "third-level management system[8]," that is, a decentralization system for curriculum of the state, region, and school, but there are many limitations in the power and freedom given to teachers in the actual development and operation of school curriculum. In addition, in terms of teachers' intrinsic aspects, difficulties such as the demands of teachers for expertise and 
lack of expertise in school curriculum development appeared. Second, as a "difficulty" in the development of school curriculum, the problems faced were different in Korea and China, as various factors such as personal and context of teachers appear differently in situations of different political and social backgrounds. Third, Korea and China face the same difficulties regarding "relationships with teachers". Like Korea, China may have different factors such as the level of human maturity of teachers in the school curriculum, philosophy and passion for education, but it is similar for Korea and China that the participation in the school curriculum development and the atmosphere of cooperation among teachers are different. Fourth, in terms of the principal's leadership, Korea and China have a common point that the principal determines the quality of school curriculum management. Fifth, in terms of the expectations of teachers in the development of school curriculum, the future of the professional profession of teachers and teachers is closely connected with the future of school. We have the expectation that we can deeply understand the needs of teachers in each school's sociocultural context.

In this study, the number of sampling to validate the result through narrative method was insufficient. The author will further continue the future development of the study.

The educational meaning and significance of the empirical stories of Korean and Chinese teachers related to the development of school curriculum in the research process so far are as follows.

First, Korea and China need to cultivate professionalism as teachers. Teachers from both countries talked about their experiences in the development of school curriculum and showed what the educational implications were. It has an educational meaning in that it reveals the process of making professional and practical knowledge as a professional worker.

Second, it has an educational meaning of ' education together' in that it indirectly reveals that there was a limit to the development of the school curriculum by discussing difficulties in relations with teachers.

Third, it can be seen that it raises the importance of diversity education that respects differences as 'individuals' with individual characteristics and diverse needs of teachers under the common demands of the times, despite the different backgrounds and policies of the country. In the spirit of educational values, teachers must do their best to develop school curriculum and to improve classroom-level curriculum.

Lastly, in the field of curriculum research, it has an educational meaning in that it is not common to study the subject of teacher narrative in the development of school curriculum in Korea and China.

\section{References}

[1] D. J. Clandinin, F. M. Connelly, Narritive lnquiry: Experience \& Story in Qualitative Research, Jossy-Bass Publishers, (2000), pp.240

[2] Young-sook Hong, Practice on Narrative Thesis Writing, Journal of Narrative and Educational Research, (2020), Vol.8, No.3, pp.7-28, DOI : 10.25051/jner.2020.8.3.001

[3] Hyeon-Suk Kang, In Search of the Value of Instructional Criticism through Teacher`s Narrative as Practical Knowledge, The Journal of Curriculum Studies, (2007), Vol.25, No.2, pp.1-35, DOI : 10.15708/kscs.25.2.200706.001

[4] Hyeon-Suk Kang, Exploring the Modern Curriculum, Seoul: Hakgisa, (2011)

[5] Ja-Eok Koo, An in-depth understanding of modern Chinese education, Seoul: Mooneumsa, (1998)

[6] Suk-Gyu Kim, Teacher's expertise, how it's made, Seoul: Sarsrimtao, (2015) 
A Comparative Study on Teacher's Narrative of School Curriculum Development in South Korea and China

[7] http://www.ippr.org/publications, Oct 10 (2011)

[8] https://wenku.baidu.com/ view/87alb93ebe23482fb4da4cd8.html, Baidu library, Jun 25 (2020) 